
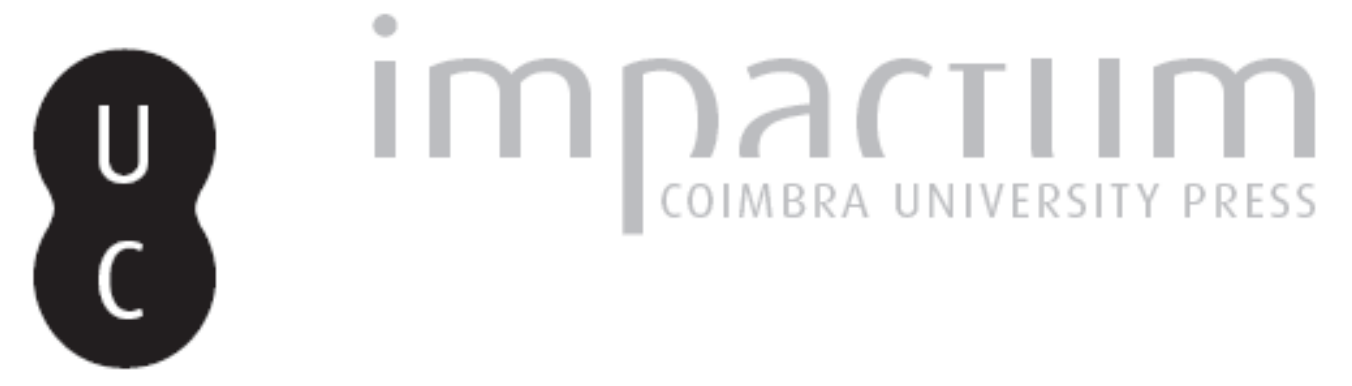

\title{
Giuseppe Cinatti: pequeno roteiro de grandes obras
}

\author{
Autor(es): Leal, Joana Cunha
}

Publicado por: Imprensa da Universidade de Coimbra

URL persistente:

URI:http://hdl.handle.net/10316.2/44979

DOI:

DOI:https://doi.org/10.14195/0870-8584_12_16

Accessed : $\quad$ 26-Apr-2023 15:39:16

A navegação consulta e descarregamento dos títulos inseridos nas Bibliotecas Digitais UC Digitalis, UC Pombalina e UC Impactum, pressupõem a aceitação plena e sem reservas dos Termos e Condições de Uso destas Bibliotecas Digitais, disponíveis em https://digitalis.uc.pt/pt-pt/termos.

Conforme exposto nos referidos Termos e Condições de Uso, o descarregamento de títulos de acesso restrito requer uma licença válida de autorização devendo o utilizador aceder ao(s) documento(s) a partir de um endereço de IP da instituição detentora da supramencionada licença.

Ao utilizador é apenas permitido o descarregamento para uso pessoal, pelo que o emprego do(s) título(s) descarregado(s) para outro fim, designadamente comercial, carece de autorização do respetivo autor ou editor da obra.

Na medida em que todas as obras da UC Digitalis se encontram protegidas pelo Código do Direito de Autor e Direitos Conexos e demais legislação aplicável, toda a cópia, parcial ou total, deste documento, nos casos em que é legalmente admitida, deverá conter ou fazer-se acompanhar por este aviso.

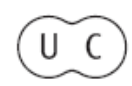




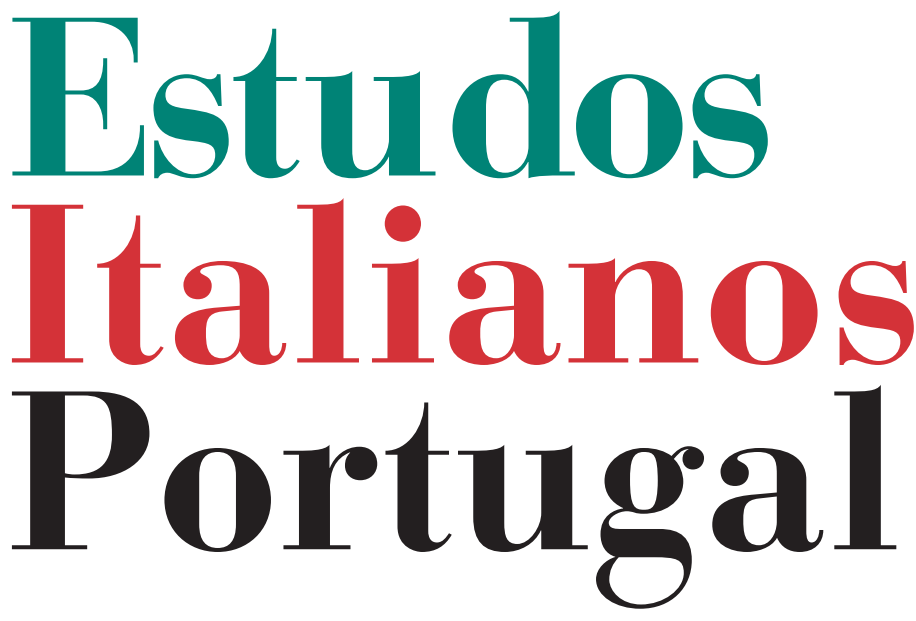

Instituto

Italiano

de Cultura

de Lisboa

Nova Série

No 12

2017 


\title{
GIUSEPPE CINATTI. PEQUENO ROTEIRO DE GRANDES OBRAS
}

\author{
Joana Cunha LeaL*
}

O MEU INTERESSE PELA OBRA do arquitecto e cenógrafo italiano Giuseppe Cinatti (1808-1879), há já alguns anos, teve por base duas inquietações. A primeira seria o facto paradoxal de a sua obra, sendo embora reconhecida como uma das mais importantes do panorama da arquitectura em Portugal no século XIX, não ter merecido qualquer estudo específico até então. A segunda, substancial, foi a tragédia do desmoronamento da torre em construção na ala conventual do mosteiro de Santa Maria de Belém em Dezembro de 1878. Cinatti era o arquitecto responsável pela construção e morreu pouco depois, ensombrado pelo desastre, configurando no meu imaginário uma espécie de anti-William Beckford, herói romântico que celebrou a ruína da sua Fonthill Abbey no dia de natal de 1825 (recém reconstruída pelo arquitecto James Wyatt). Foi a imagem desse falhanço monumental na era do progresso tecnológico que tornou a figura do italiano irresistível para mim, e nesses anos de meados da década de 1990, dediquei-me,

*Professora Auxiliar do Departamento de História da Arte da FCSH-NOVA e Investigadora do Instituto de História da Arte (IHA) da mesma Universidade, que actualmente dirige. $\mathrm{O}$ seus trabalhos mais recentes privilegiam o estudo dos modernismos e das vanguardas ibéricas. Foi bolseira Fulbright em 2010 e IR do projecto Southern Modernisms financiado pela FCT em 2015. j.cunhaleal@gmail.com 
semi-enamorada, a resgatar a sua obra numa tese de mestrado $^{1}$. Num plano historiográfico, o resgate passaria por discutir a legitimidade da entrega da obra de restauro e reconstrução de Belém a Cinatti, enfrentar a dúvida relativa às suas habilitações e, por extensão, o empolamento negativo da sua condição de cenógrafo.

O desastre de Belém dá à obra de Cinatti uma dimensão simbólica que vai muito para além do que especificamente produziu em Lisboa e Évora. Na verdade, ela contribuiu para obscurecer a sua obra de arquitecto, fundamentando quer o argumento de uma endémica imprudência, se não incompetência, nacional em termos de conservação do património, quer um conjunto de ideias dominantes sobre a arquitectura (e a arte) do século XIX, como por exemplo a má formação dos profissionais, a desadequação do ensino artístico e a falência da cultura estética nacional ${ }^{2}$.

Não se trata aqui de discutir qualquer argumento geral sobre a arte em Portugal no século XIX, nem de analisar a totalidade da obra arquitectónica de Giuseppe Cinatti, mas tão só de reconstituir, à maneira de um pequeno roteiro, alguns dados sobre o seu percurso e de elucidar, com base nesse percurso, os termos da sua contratação para as obras de restauro e complemento da igreja e mosteiro de Santa Maria de Belém. Comecemos, pois, pelo início que, para nós, coincide com a sua chegada a Lisboa.

${ }^{1}$ Toda a investigação e respectivo aparato de documentação histórica a que este texto se reporta foi apresentado e discutido em 1996 no âmbito da dissertação de mestrado que defendi no Departamento de História da Arte da FCSH-NOVA. Ver Joana Cunha Leal, Giuseppe Cinatti (1808-1879). Percurso e obra, Tese de Mestrado em História de Arte Contemporânea apresentada à FCSH da Universidade Nova, Lisboa, 1996, 2 vols. O volume de texto é, daqui para a frente, citado como GC.

${ }^{2}$ José-Augusto França, $A$ arte em Portugal no Século XIX, Venda Nova, Bertrand, 1974,2 vols. 
Milāo - LisBoA

Giuseppe Cinatti chegou a Lisboa no início do ano de $1936^{3}$. Tinha 28 anos e sobrevivera a uma aventurosa travessia dos Alpes em pleno Inverno, em fuga de Milão, motivada pela sua recusa em executar um opositor político (GC: 15-29). Trazia então uma formação arquitectónica com a chancela da Accademia di Brera, temperada quer da prática de pintor decorador associada à profissão de seu pai, quer da passagem por Lyon onde, muito possivelmente, pela primeira vez trabalhou como cenógrafo.

Cinatti terá sido contratado para o São Carlos precisamente na Ópera de Lyon. E é já em Lisboa que encontra o companheiro de todo o seu percurso profissional: o cenógrafo Achille Rambois. Rambois chegara a Lisboa dois anos antes, depois de uma estreia no próprio Teatro alla Scala onde os anos de formação no célebre Pateo de Miláo o tinham levado (GC: 29). Os sucessos da dupla que se forma entre Cinatti e Rambois a partir de então são relativamente bem conhecidos. Dir-se-ia que apesar dos anos de agitação política em Portugal, ambos encontraram aqui uma atmosfera propícia ao desenvolvimento do seu trabalho e decidem fazê-lo em conjunto, primeiro como cenógrafos, depois como pintores-decoradores e finalmente como arquitectos.

A inserção de Cinatti como pintor cenógrafo no círculo social da ópera e depois do Teatro de D. Maria II, longe de ter constituído um obstáculo à sua prestação futura como arquitecto, foi pelo contrário um importante trunfo para a sua aproximação às elites do Liberalismo. É o prestígio do trabalho que desenvolvem no campo da pintura cenográfica que conduz Cinatti e Rambois à remodelação de interiores palacianos, primeiro para os duques de Palmela no palácio do Calhariz (a partir de 1842) e logo depois para a família

\footnotetext{
${ }^{3}$ Giuseppe Cinatti nasceu em Siena em 1808, filho de Luigi Cinatti, pintor decorativo activo na Lombardia; GC, p. 15 (n. 1 a 3).
} 
real no palácio das Necessidades (1844-1846) ${ }^{4}$. Neste último caso, estaria em causa já não apenas a concepção de novos programas decorativos, mas também a concepção de novos espaços.

Já na década de 1850 Cinatti irá projectar um significativo conjunto de palacetes para a grande burguesia lisboeta. É do seu risco que saem alguns dos mais marcantes edifícios de habitação na zona nobre do Chiado, muito particularmente nas imediaçóes do Largo da Academia das Belas Artes. O palacete de Tomás Maria Bessone, por exemplo, na actual Rua Vítor Cordon, ou o palacete que os irmãos Iglésias edificaram mesmo em frente, sobre as ruínas da antiga igreja do convento de São Francisco (a fachada principal está alinhada com a do edifício da Academia de Belas Artes, tornejando o edifício para a Rua Vítor Cordon). Ambos os projectos foram aprovados pela Repartição Técnica da Câmara de Lisboa em 1856. No outro extremo da Rua Vítor Cordon (tornejando para a actual Rua António Maria Cardoso), coube também a Giuseppe Cinatti a construção do conjunto de dois imponentes prédios nobres de rendimento desenhados para a Casa de Bragança e aprovados pela mesma Repartição da Câmara em 1858.5

Ainda nesse ano de 1858, Cinatti seria chamado pela primeira vez a Évora a fim de construir a nova morada de José Maria Ramalho Diniz Perdigão (palácio Barahona). Nada

\footnotetext{
${ }^{4}$ GC: 85 . A qualidade da intervenção no palácio lisboeta dos Palmela, asseverada pelo conde A. Raczynski, poderá ter influenciado a escolha do arquitecto italiano para a direcção de parte dos trabalhos de remodelação do palácio das Necessidades. Estas obras visaram adaptar o edifício a morada permanente de D. Maria II e D. Fernando. Sobre o alcance estrutural das obras dirigidas por Cinatti ver GC: 87 ss. Outro arquitecto envolvido na remodelação foi Joaquim Narciso Possidónio da Silva.

${ }^{5}$ Já na década de 1860, Cinatti construirá o palacete de Manuel Nunes Correia na Avenida da Liberdade (sede actual da EPAL) e o palacete de Policarpo Anjos na Rua da Escola Politécnica. Já nos anos 1870 destaca-se a casa de veraneio de António José Lopes Ferreira dos Anjos em Sintra.
} 
faria prever, então, o papel determinante que o arquitecto italiano iria assumir no processo de renovação urbana e no restauro dos principais monumentos da cidade alentejana ao longo da década seguinte. $\mathrm{O}$ conjunto integrado das obras realizadas em Évora esteve, por sua vez, e como veremos, na base da sua contratação pelo Provedor da Casa Pia de Lisboa para o restauro e reconstrução do mosteiro de Santa Maria de Belém. Assim, se se pode pensar que o prestígio das moradas que concebeu para as elites da capital em final dos anos 1850 terá justificado o investimento de José Maria Ramalho na sua contratação para Évora, é sem dúvida o sucesso das intervenções no espaço público e no património eborenses que justificará o seu regresso a Lisboa, já não apenas como arquitecto de palacetes, mas como responsável pela intervenção num dos mais venerados monumentos nacionais.

Quer isto dizer que a direcção das obras de Bélem, atribuída por José Maria Eugénio de Almeida, Provedor da Casa Pia, a Giuseppe Cinatti, só pode ser compreendida num quadro mais vasto que implica olhar primeiro, e sobretudo, para as obras que levou a cabo em Évora.

\section{LisBOA-ÉVORA}

Cinatti chegou a Évora em 1858. O momento precede a transformação radical da cidade associada à chegada do caminho de ferro, em 1863. Conduzido a Évora por um dos seus cidadãos mais proeminentes, a acção do arquitecto italiano começou por mudar o aspecto daquela que se tornaria, nesse momento, a mais importante entrada na cidade: a porta do Rossio de São Brás. Incrustada na muralha, a nova morada de José Maria Ramalho beneficiou da sua implantação sobre o vasto terreiro do Rossio, sobressaindo aos olhos de todos quantos, vindos da estação dos caminhos de ferro, se dirigiam à cidade fortificada. 
As negociações entre José Maria Ramalho e a Câmara de Évora para o alargamento da sua propriedade, a fim de "edificar a sua residência e dar à rua um maior embelezamento" tiveram início ainda em 1856, tendo o lavrador conseguido o aforamento uma parte dos terrenos baldios do Rossio de São Brás em Julho de 1863 (GC: 203). Ramalho garante o usufruto desses terrenos a fim de "evitar cenas indecentes, e até mesmo imorais, que o recanto do Rossio - contíguo à casa nobre em construção - pela sua forma facilita" ${ }^{\text {. }}$. Comprometia-se, em contrapartida, a ajardinar o local, de modo a contribuir para o embelezamento da cidade. Ora, as iniciativas de renovação desta parte da cidade financiadas por José Maria Ramalho não se ficariam por aqui. O "lavrador" assumiria também as despesas com a remodelação da própria porta da cidade, cuja alteração foi autorizada pelo Ministério da Guerra em Março de 1863. A obra foi, é claro, entregue a Giuseppe Cinatti, que desenhou a nova porta respeitando requisitos de alargamento e monumentalização. As duas colunas monumentais adossadas à muralha, coroadas por esferas de evocação manuelina, que desde então compóem a porta do Rossio, seriam a primeira obra do arquitecto italiano no espaço público da cidade alentejana.

Outro importante projecto de melhoramento se associou no imediato a este: a ideia da construção de um jardim público na área do baluarte do Príncipe, isto é nos terrenos para onde dava a fachada principal do novo palacete. As primeiras referências à obra do então designado "jardim das Amoreiras" surgem nas Actas do Município, igualmente nesse ano chave de 1863, no resumo oficial da reunião de vereação em que precisamente ficara decidida a demolição da velha porta do Rossio. Ou seja, a construção do Passeio Público de Évora esteve, desde as suas mais remotas origens, ligada à obra do palacete de José Maria Ramalho e ao seu arquitecto. A construção do parque público foi inicialmente financiada

\footnotetext{
${ }^{6}$ GC: 267 . A construção do palacete teve início em 1859.
} 
por Ramalho e entregue a Cinatti, que projectou o jardim e dirigiu as obras pro bono.

Abria-se aqui, para o arquitecto, um campo novo de intervenção na cidade, marcado pela colaboração directa com a Câmara Municipal e por um avolumar das responsabilidades que lhe foram sendo atribuídas. É que, muito rapidamente, o projecto do novo parque passaria a incluir não apenas a configuração do jardim, mas também a transformação de toda a área da cidade contígua ao Convento de São Francisco, o que por sua vez implicava o destino de monumentos importantes do património nacional, como a Galeria das Damas, ou Trem, e as instalações paçãs e conventuais de São Francisco ${ }^{7}$.

$\mathrm{O}$ projecto integrado de intervenções, que ganharia entretanto visibilidade nacional com a inauguração do caminho de ferro, viu as várias contingências que poderiam ter dificultado a sua concretização (muito particularmente o facto de os edifícios do palácio real estarem na posse do Ministério da Guerra) ${ }^{8}$ rapidamente ultrapassadas. Mas mais do que isso, o decreto de 25 de Julho de 1864 atribuirá à Câmara de Évora a responsabilidade de, num prazo de três anos, restaurar os edifícios que passavam para a sua posse, destinando-os a novas funções (tribunal judicial, escola nocturna, serviços municipais), e abrir uma praça à frente da igreja de São Francisco "que desafronte a entrada do templo e a aformoseie"

\footnotetext{
${ }^{7}$ A reconversão da área traria também a oportunidade de construção de um novo equipamento, a saber, o novo mercado que a cidade carecia (GC: 270-271).

${ }^{8}$ Vindo a Évora para a inauguração do caminho de ferro em Setembro de 1863, o Ministro da Guerra, então o marquês Sá da Bandeira, testemunhou o curso das obras de construção do jardim das Amoreiras e da nova porta do Rossio. Aparentemente impressionado com o plano dos melhoramentos riscados por Cinatti, o ministro terá contrubuído em Lisboa para reforçar as pretensōes da Câmara de Évora (GC: 272).

${ }^{9}$ Diário do Governo, 154 (14-06-1864) (CG: 272). Esta ordem estaria na origem da demolição da parcela do aqueduto da Água de Prata e da torrinha quinhentista desenhada por Francisco de Arruda que a coroava, que corria colada à galilé da igreja. Será um dos crimes lesa-património mais graves deste século e Giuseppe Cinatti não esteve directamente envolvido nele (GC: 280-281).
} 
Notemos para já que a operação de renovação urbana orquestrada por Cinatti com a Câmara de Évora acabaria necessariamente por converter-se numa obra de intervenção patrimonial, já que o Decreto impunha a re-funcionalização e restauro da Galeria das Damas e das instalaçóes do Convento de São Francisco. Pelo que Cinatti deixava de ser apenas o director da obra de ajardinamento para ser o arquitecto-restaurador desses edifícios históricos.

Um espírito de salvaguarda patrimonial estaria ainda na base da construção das célebres, e hoje muito mal tratadas, ruinas fingidas do Passeio Público. O monumento contemporâneo oferecido por Cinatti à cidade tratou não apenas de valorizar a torre trecentista que subsistia num recanto do jardim, mas também de reintegrar um conjunto de janelas do século XVI de feição mudéjar, retiradas do antigo palácio dos Vimioso na sequência das obras de reconstrução levadas a cabo, em 1863, pelos seus novos proprietários (GC: 275-276). Disposto de modo a permitir o acesso à plataforma cimeira da torre, o conjunto funcionava também como miradouro de onde se podia fruir uma vista sobre toda a área intervencionada.

O restauro da Galeria da Damas e dos edifícios do antigo paço e convento de São Francisco foi, como disse atrás, executado sob a direcção do arquitecto italiano. Estávamos já em vésperas do termo do prazo de três anos estipulado no decreto de 1864. A penúria endémica dos cofres da Câmara explica, em grande medida, a demora das obras e, finalmente, a redução da intervenção a necessidades prementes (GC: 276-277). Exceptuando obras de consolidação da Galeria das Damas - obras pouco dispendiosas, mas de algum impacte visual, sobretudo porque as janelas foram desobstruídas -, e de criação de condições mínimas para o funcionamento do tribunal em São Francisco, nada se cumprira ainda do projecto de restauro e re-funcionalização da ala paçã e conventual anexa à igreja de São Francisco. Só em 1870 Cinatti apre- 
sentaria os planos que iriam regular, final e definitivamente, o desenvolvimento da intervenção nos edifícios contíguos ao Passeio Público ${ }^{10}$.

Entretanto, o benefício da obra do Passeio era plenamente reconhecido, a ponto de a vereação eleita para o biénio de 1866-1867 ter tido a preocupação de garantir a continuidade da colaboração do arquitecto italiano11. Pouco depois, enquanto se contabilizavam os resultados de uma subscrição pública destinada a cobrir os custos do gradeamento do novo Passeio, esta mesma vereação proporá que seja dada "ao ilustre artista José Cinatti uma prova bem pública da consideração e estima em que o tem pelos relevantes serviços prestados ao Município de Évora na direcção e construção de um dos melhores passeios do país, qual é o passeio público desta cidade que se acha quase concluído, tendo-se prontificado a vir a esta cidade por muitas vezes com graves prejuízos seus, sem que para isso tenha requerido remuneração alguma, nem mesmo o preço das viagens" 12 .

${ }^{10}$ É impossível avaliar-se a qualidade e extensão da intervenção de Cinatti nos espaços do paço e do convento franciscano, não só porque os desenhos não são conhecidos, mas também porque nenhuma das salas chegou aos nossos dias. Acresce o facto de, paralelamente a estas obras, terem decorrido outras, a cargo do engenheiro da Repartição Técnica das Obras Públicas de Évora, Caetano da Câmara Manoel. Foi sob a direcção deste engenheiro que decorreram, a partir de 1869, as obras de desafrontamento da praça fronteira à igreja de São Francisco, com a consequente demolição de parte do aqueduto da Água de Prata. Cinatti foi, depois, chamado pela Câmara para recompor a galilé da igreja, afectada pela acção de desafrontamento (GC: 279-281).

${ }^{11}$ Decide-se por unanimidade o envio de um ofício "ao cavalheiro Cinatti, pedindo-lhe para esta Câmara igual cooperação que prestou à transacta na construção do Passeio Público, auxiliando-a com os seus conselhos e direcção, para que não se altere o risco do mesmo, e para que a obra seja acabada de uma maneira digna de quem a começou", Sessão de 8 de Janeiro de 1866, Arquivo Distrital de Évora, Livro n. $^{\circ} 71$ das Actas da Câmara Municipal de Évora: 1864-1866, fls. 84v-85 (CG: 277-278).

${ }^{12}$ Sessão de 19-12-1867; Arquivo Distrital de Évora, Livro n. ${ }^{\circ} 72$ das Actas da Câmara Municipal de Évora: 1866-1869, fl. 65. Acordada ficou então a oferta de uma medalha de ouro "tendo de um lado as armas da cidade e do outro a seguinte legenda: 'A José Cinatti a cidade de Évora reconhecida” " (CG: 278). 
Já em 1871, no momento em que se concluía a construção do Passeio Público, prolongado numa segunda fase pela plantação de uma mata no baluarte do Conde de Lippe, e aprovava em sede de vereação o regulamento da sua utilização (GC: 282), Giuseppe Cinatti seria envolvido num outro importante processo de intervenção patrimonial, assumindo o restauro do templo romano, dito de Diana.

O templo de Diana chegara ao século XIX completamente adulterado, transformado que fora numa espécie de torre por via do enchimento dos espaços inter-colunas com paredes de alvenaria e de um coroamento ameado. Serviu de açougue municipal desde meados do século XIV, e foi mantido nessas funçôes até 1836, data em que o Governador Civil do Distrito de Évora, António José de Âvila, mandou cessar "aquela ignóbil aplicação de tão venerando monumento" (GC: 283-284).

$\mathrm{O}$ restauro, dirigido por Cinatti, acabou por seguir as orientaçôes sugeridas pelo Director da Biblioteca Pública de Évora e do Museu Cenáculo, o arqueólogo Augusto Filipe Simões, de que os panos de muro e todos os acrescentos fossem retirados ao monumento ${ }^{13}$.

A determinação em reintegrar o Templo de Diana libertando-o dos acrescentos fora claramente apoiada por uma consulta dirigida pela Câmara de Évora a um conjunto de figuras tidas como capazes de dar um contributo relevante

${ }^{13}$ O Museu Cenáculo fora entretanto instalado no templo e será a propósito da remodelação do museu que, pela primeira vez em 1969, a reintegração do monumento é sugerida pelo arqueólogo. Afastando a possibilidade de recuperação do monumento tal como se encontrava, uma vez que o "concerto de todo o edifício tal como está, além de muito dispendioso parecia de mau gosto aos entendidos por perpetuar um vandalismo que nunca deveria ter existido", Augusto Filipe Simões propõe à Câmara de Évora uma intervenção que recuperasse a estrutura original do edifício. O seu parecer foi apresentado como tendo merecido o acordo "de todas as pessoas conhecedoras das belas artes que têm vindo a Évora”, bem como dos engenheiros de obras públicas do distrito. Reporta ainda a opinião de Cinatti que a seu pedido fora examinar o monumento, para concluir "que se deveria demolir tudo o que não fosse romano.". Ver Augusto Filipe Simões, Relatório ácerca da renovação do Museu Cenáculo, Évora, Tip. Folha do Sul, 1869; CG: 286. 
para a ponderação das demolições em vista ${ }^{14}$. Incluído neste grupo estava o Provedor da Casa Pia de Lisboa, José Maria Eugénio de Almeida, que desde 1859 tinha sob sua responsabilidade as obras de reintegração e restauro do Mosteiro de Santa Maria de Belém (GC: 293). A estreita ligação que Eugénio de Almeida manteve com a cidade de Évora, em cujo distrito tinha cerca de 40 propriedades agrícolas (além de vários negócios com José Maria Ramalho), não pode ter sido indiferente à chamada de Giuseppe Cinatti para a direcção das obras dos Jerónimos a partir de 1867. Ao mesmo tempo, o arquitecto prestaria provas na construção das cocheiras do Parque de Santa Gertrudes, que completava o palácio de São Sebastião da Pedreira, reconstruído a partir de 1859 por Eugénio de Almeida para sua morada (GC: 215 ss).

\section{LISBOA - BELÉM}

Quando aceitou a nomeação para Provedor, a Casa Pia de Lisboa atravessava uma profunda crise. Eugénio de Almeida gizou um plano para a recuperação da instituição com total autonomia, assentando a sua acção em três vectores fundamentais: viabilização económica (conseguida à custa da redução do número de internados em cerca de 50\%) e reorganização administrativa; reforma do ensino; e reforma do edifício segundo um projecto global que, para além de privilegiar o bem estar dos órfãos, cumprisse também um programa de intervenção patrimonial (GC: 293-294). Do resumo de intenções apresentado pelo Provedor no balanço do seu primeiro ano à frente da Casa Pia, destaca-se, assim, a ideia de que a ala conventual e a igreja de Santa Maria de Belém permaneciam inacabadas, pelo que seria absolutamente necessário providenciar o seu acabamento (GC: 294-295). Ou seja, a

${ }^{14} \mathrm{O}$ grupo das personalidades consultadas incluía professores da Academia de Belas Artes, o seu Presidente, o arquitecto Joaquim Possidónio da Silva, vários historiadores, etc. (CG: 288-289). 
par da melhoria das instalações destinadas aos órfãos, Eugénio de Almeida avançava com a ideia do acabamento e, por extensão, o engrandecimento do monumento, propondo também a limpeza de todas as construções posteriores, corruptoras do estilo original (precisamente nos termos em que defende depois a reintegração do Templo de Diana em Évora).

Ao mesmo tempo que programava a intervenção em Santa Maria de Belém, Eugénio de Almeida avançou para a construção de uma nova morada familiar. Comprou para tanto o antigo palácio do Provedor dos Armazéns no largo de São Sebastião da Pedreira, ao qual anexou a vasta Quinta da Provedoura. A partir destas propriedades, com uma área total de $86000 \mathrm{~m} 2$, Eugénio de Almeida reconstruiu o palácio e criou o Parque de Santa Gertrudes (hoje correspondente aos jardins da Fundação Calouste Gulbenkian). Cinatti seria chamado a riscar o edifício acastelado das cocheiras (GC: 215). Estávamos já uns anos depois do início das obras de reconstrução do palácio, entregues ao arquitecto Jean Colson, mas Eugénio de Almeida seguia o mesmo procedimento de experimentar nas obras da sua casa os arquitectos que depois transportava para Santa Maria de Belém. Assim aconteceu com o francês Colson, o português Valentim José Correia e o italiano Giuseppe Cinatti ${ }^{15}$.

As cocheiras desenhadas por Cinatti para o Parque de Santa Gertrudes substituíram a proposta traçada por Valentim José Correia em 1864 (GC: 226-227). Renunciando a qualquer ordem simétrica, o edifício recupera, miniaturizando-o, o aspecto de um castelo medievalizante (com ameias, guaritas poligonais e torre), em harmonia com o gosto pitoresco do parque plantado à inglesa, e com os trabalhos que por esses anos Cinatti desenvolveu em Évora (a construção das ruinas fingidas, por exemplo) ${ }^{16 .}$

\footnotetext{
${ }^{15}$ GC: 298 ss. O único caso em isso não acontece é o do britânico Samuel Bennett, que é contratado para Belém em 1865, substituindo Valentim José Correia (GC: 313).

${ }^{16} \mathrm{O}$ edifício seria posteriormente adaptado a habitação, todavia o desenho original das cavalariças e cocheiras permanece no espólio familiar (CG: 228).
} 
Em 1867, Cinatti é chamado a dirigir as obras de Belém, iniciadas muito antes. $\mathrm{O}$ ano da sua chegada (e de Rambois) coincide com o da apresentação do projecto para restauro da igreja manuelina pelo arquitecto Joaquim Possidónio da Silva que, se fica a saber, partilhava com o Provedor a ideia de que o monumento ficara incompleto e que era necessário libertá-lo das alterações introduzidas em épocas posteriores (o que no caso especifico da igreja, incluía a capela mor desenhada por Jerónimo de Ruão). Esta iniciativa do arquitecto português não teve qualquer reconhecimento por parte de Eugénio de Almeida que, na realidade, só obteria autorização do governo para intervir na igreja dois anos mais tarde. Ou seja, Cinatti liderava já as obras quando o Ministério das Obras Públicas, dedicando os maiores elogios à acção de Eugénio de Almeida, o encarrega de "concluir o exterior de templo tão notável, harmonizando-o com o edifício contíguo do extinto convento dos Jerónimos destinado à Casa Pia de Lisboa", ao mesmo tempo que atribuía às obras uma prestação mensal de $500000 \$ 000$ réis (elevada logo depois para 1 conto de réis) ${ }^{17}$.

É neste contexto muito favorável que avançam algumas demolições (como o corpo de ligação entre a igreja e a ala conventual, onde se encontrava a sala dos reis) e surgem novas construçôes delineadas por Cinatti (como a célebre cúpula que coroa a torre da igreja). Mas é sobretudo neste contexto que veremos crescer o novo corpo central da ala conventual. Este exercício revivalista que não cessará de se apurar e elevar - e ainda muito mais após a morte de Eugénio de Almeida em 1872 e da atribuição do cargo de Provedor a seu filho, Carlos Maria Eugénio de Almeida -, a ponto de desafiar a estabilidade dos alicerces afundados num terreno arenoso. No momento em que se erguia a Agulha do Corpo Central, em Julho de 1878, assinalam-se os primeiros sinais de instabilidade da construção que acabaria por ruir com-

${ }^{17}$ Ofício do Ministério das Obras Públicas de 02-10-1869 (GC: 319-320). 
pletamente a 18 de Dezembro desse mesmo ano (GC: 327 ss.). Fecha-se assim o ciclo de trabalho de Cinatti como arquitecto. Cinatti morreria aliás logo depois, em 1879, inconsolável pela dimensão da tragédia. Este falhanço final pode ser discutido em muitos termos: condiçóes do terreno, ou o insustentável agigantamento da arquitectura, por exemplo. Mas o que este pequeno roteiro das grandes obras ajuda a demonstrar, espero, é que em nenhum momento podemos assumir a nulidade do percurso arquitectónico de Cinatti, nem mesmo no campo patrimonial. 